\title{
Proceeding
}

Supplementary Issue: Autumn Conferences of Sports Science. Costa Blanca Sports Science Events, 18-19 December 2020. Alicante, Spain.

\section{Predicting of a person's life activity through quantitative indicators of her personal profile in social networks (on the example of predicting the academic success of students)}

\author{
PAVEL N. USTIN U, LEONID M. POPOV, RUSLAN N. KHAKIMZYANOV, GALIM Z. VAKHITOV \\ Institute of Psychology and Education, Kazan (Volga Region) Federal University, Kazan, Russian Federation
}

\begin{abstract}
The object of this paper is to identify psychological patterns of academic success of an individual as a manifestation of his life activity, based on the analysis of quantitative indicators (metrics) of his profile in social networks. The leading method of research was an ascertaining experiment that included diagnostics of students' academic success $(\mathrm{N} \approx 30000)$ and components of their personal profile in social networks (psychometrics). The article shows the features of interaction between real and virtual activity of students through quantitative indicators of their personal profile metrics in social networks. The presented materials significantly fill the psychology of social networks (a new field of psychology, which is at the initial stage of its forming) with knowledge about the psychological regularities of the correlation of academic success of a person with the characteristics of her virtual activity in social networks. The project is implemented within the framework of intensive development of digital technologies and their deep integration into the social space. The results of the study expand the possibilities for diagnosing, analysing, understanding, and predicting the behaviour of a person's success through cyberspace on the example of their academic performance. The scientific novelty of this research consists in the identification of cognitive-behavioural predictors of educational activity of an individual, which are represented in virtual reality, as the result of his activity in social networks through quantitative psychometric indicators - metrics of his personal profile in social networks.

Keywords: Personality; Behaviour; Virtual behaviour; Social networks; Prognostics; Life activity; Academic success; Psychometrics; Predictors; Neural networks; Students.

Cite this article as:

Ustin, P.N., Popov, L.M., Khakimzyanov, R.N., \& Vakhitov, G.Z. (2021). Predicting of a person's life activity through quantitative indicators of her personal profile in social networks (on the example of predicting the academic success of students). Journal of Human Sport and Exercise, 16(2proc), S377-S386. doi:https://doi.org/10.14198/jhse.2021.16.Proc2.22

Corresponding author. Institute of Psychology and Education, Kazan (Volga Region) Federal University, Kazan, Russia.

E-mail: livelybabak@yahoo.com

Abstract submitted to: Autumn Conferences of Sports Science. Costa Blanca Sports Science Events, 18-19 December 2020. Alicante, Spain.

JOURNAL OF HUMAN SPORT \& EXERCISE ISSN 1988-5202

(c) Faculty of Education. University of Alicante

doi:10.14198/jhse.2021.16.Proc2.22
\end{abstract}




\section{INTRODUCTION}

The processes of active integration of the digital environment into the real life of people highlight new research problems related to the study and analysis of human behaviour in the conditions of virtual interaction. This work is devoted to the problem of studying the possibilities of assessing and predicting the life activity of an individual in educational activities through the features of his virtual behaviour in social networks. This problem relates to a wide range of issues associated with «Cyber-psychology» - a new science direction, the emergence of which is demanded by the logic of the development of the modern information society and the general strategy for the development of scientific knowledge for the coming decades. Given the current role of virtual reality in people's lives and the revolutionary opportunities it provides for the development of psychological theory and practice cyber-psychology is a leading trend in the coming decades. Within this trend, a special place is occupied by the psychology of social networks - one of the most intensively developing areas.

The activity of modern people in social networks is one of the main forms of their interaction with the world around them through virtual space (Lam, 2015; Lau, 2018; Solmaz, 2018; Karakoyun, 2019; Mwangi, Gachahi, \& Ndung'u, 2019; Owan, Ekpe, \& Eneje, 2020; Radwan \& Radwan, 2020; Simsek, Elciyar \& Kizilhan, 2019; Mulenga, \& Marbán, 2020; Baishya, \& Maheshwari, 2020). In the annual report of the American Psychological Association (APA), the use of social networks (i.e., the digital environment) and Big Data opens up broad prospects for approaching the understanding of such a complex and multidimensional phenomenon as human behaviour in the real world. According to the results prepared by the analytical Agency «Statista», only Facebook, as one of the most popular social networks, includes more than 2 billion users in the world. In Russia, according to a 2018 survey by the Russian Public Opinion Research Center (VCIOM), the majority of people (at least $62 \%$ ) have social media accounts and about half (at least $45 \%$ ) of citizens over the age of 18 use them almost every day. At the same time, one of the most popular virtual platforms among Russians is the "Vkontakte» - social network, where most users have active accounts. Thus, according to the PRT Agency, more than $80 \%$ of Russians aged 19 to 30 years have their own account in this social network.

Virtual activity in social networks allows its users to carry out both face-to-face and correspondence interaction with an unlimited number of people, regardless of spatial and temporal boundaries. The core link in the social network is the personal profile of its user - an analogue of a virtual personality, where various information is placed and visualized (biographical information, work experience, their interests, etc.). The features of a virtual person, in turn, are associated with the features of a real person and are presented in the form of its psychometric profile elements on its personal page (number of friends, posts, photos, videos, audio recordings, subscribers, etc.).

In psychology, research related to the problem of personality in social networks is noted after the appearance of the first social services such as «Facebook» (2004-2006); «Odnoklassniki» (2006), «VKontakte» (2006). Since 2006, works have begun to appear that reveal the relationship between the characteristics of real and virtual personality and related to the possibility of predicting human behaviour based on psychometric data of his personal profile in social networks. Thus, in a study of Palestinian scientists (Zyoud et al., 2018) based on the analysis of more than 11,000 publications devoted to the problem of social media, more than 1,000 works related to the psychology of social networks were identified.

Most of works associated with the psychology of social networks are focused on the "myPersonality project", which is coordinated by the Psychometrics Center at the University of Cambridge. This project is aimed at 
studying the psychological and demographic profiles of users of the social network "Facebook" and brings together more than 200 researchers from around the world. The main vector of research is related to the predictive capabilities of social networks, where the authors show how to diagnose psychological characteristics of a person based on various indicators of the user's personal profile (objective indicators) and predict its behaviour. To date, the authors have identified various indicators (psychometrics) that are associated with the activity of a person in real life and allow to predict (with a certain degree of probability) her behaviour based on digital traces in social networks.

One of the known examples is the result of a study in the Psychometrics Center, where a sample of more than 58,000 Facebook users showed the predictive capabilities of "likes" in social networks. Researchers have shown that based on "likes" you can predict: race (African-Americans or Europeans) with a 95\% probability; gender (male or female) with a $93 \%$ probability; sexual orientation with an $88 \%$ probability for men and $75 \%$ for women; party affiliation (Republicans or Democrats) with an $85 \%$ probability; religious affiliation (Muslim or Christian) with an 82\% probability (Kosinski, Stillwell \& Graepel, 2013).

Studies of correlations of various indicators of virtual activity of a social network user with his psychological characteristics reveal the possibility to describe the psychological portrait of a person and predict numerous aspects of his behaviour. Among the indicators of activity of users of social networks are analysed: the overall level of use's virtual activity in social networks, features of interaction of a person in virtual communication with other users, the openness of the individual in social networks, the content of posts and messages of a user in his personal profile, frequency of status updates profile, frequency of posting "selfies", the number of friends, etc.

Among the psychological characteristics researchers analyse different variables. As an examples: the correlation between personal profile indicators with extroversion (Seidman, 2013); correlation with gender (Hung, 2020); correlation with self-esteem (Blomfield Neira \& Barber, 2014); correlation with emotional States (Sorokowski et al., 2015); correlation with narcissism (Große, Mehl \& Eid, 2014); correlation with social activity in real life (Hung, 2020); correlation with well-being (Manago, Taylor \& Greenfield, 2012); correlation with self-esteem (Tazghini \& Siedlecki, 2013).

Among other studies of the problem of predicting human behaviour using various indicators (metrics) of his personal profile in social networks, the following works can be noted. The work of M. Kosinski (2017) about predicting possible behavioural reactions of a person through the coefficients of the ratio of the parameters of his face: width to height and the work about predicting sexual orientations of a person through its photo images (Wang \& Kosinski, 2018). L. Chen et al. (2017) with a group of researchers assessed life satisfaction of person through analysing updates of its status in Facebook. The work of a number of researchers about predicting the user's gender, age, and personality traits through the frequency of their use of words and phrases in social networks (Schwartz et al., 2013). The study of the possibilities of predicting personality characteristics through the assessment of its musical preferences in social networks (Nave, Minxha \& Greenberg, 2018; Kislyakov et al., 2020).

In this paper the studied variable is academic success - which is one of the indicators of a person's life activity. 


\section{METHODS}

\section{Purpose of research}

To identify psychological patterns of academic success of a person as a manifestation of her life activity based on the analysis of quantitative indicators (metrics) of her profile in social networks.

\section{Methods of research}

The study is based on a comprehensive approach and combined the efforts of specialists in psychology and information technologies.

The theoretical part of the study was based on the following methods: analysis, synthesis, generalization, and modelling. The leading method of empirical data collecting was the ascertaining experiment. Empirical data was collected using Information - Analytical system for monitoring student's personal pages developed by information technology specialists. Processing and interpretation of the results was carried out by methods of mathematical statistics (descriptive statistics, correlation analysis).

\section{Experimental base of the study}

The research was carried out on the basis of the Kazan Federal University. The total number of respondents was more than 30000 students from all institutes and faculties of the University. The study involved bachelors studying in the first, second, third and fourth years and masters studying in the first and second years. Data on students was formed using the Information - Analytical system "Student" (Electronic University).

The ethical aspects of the study were achieved through the registration of consents to work with personal data. Also, student's personal data formed in the databases were anonymized.

\section{Research stages}

At the first stage, a theoretical analysis of the problem of identifying psychometric indicators of personality behaviour through the features of its virtual activity in social networks was carried out.

The second stage was carried out preparatory procedures for the organization of an experimental study: the formation of database of students, making agreements on personal data processing, development of Information-Analytical system for monitoring personal pages and for subsequent anonymization results.

At the third stage, an experimental study and structuring of the experimental database of students was carried out. The results of the study were processed using mathematical statistics and interpreted.

\section{Findings}

At the first stage of the research, it was found that the virtual activity of students in social networks includes: communication and exchange of information, cognition, professional and leisure activities, and creativity. The results of this personality activity in social networks (control points of virtual personality activity) are its cognitive and behavioural acts (processes) and products (results), presented in the form of attributes of its personal profile in social networks - personal profile metrics. These are: posts (both creating your own and distributing someone else's); "likes" (assessment of the virtual activity of other users of social networks); creating, transferring, and storing audio-video-photo content; participating in social communities, etc.

Thus, the main prognostic tool that allows to evaluate the features of the virtual activity of users of social networks are the metrics of their personal profile. Moreover, these metrics are the point of interaction between 
the "real Self" and the "virtual Self'. The category "Interaction" as a reflection of the life activity of the individual, is the most accurate and correct form of describing the mechanism that connects the "real Self" with the "virtual Self". In turn, the products of the cognitive-behavioural plan, which are reflected in the metrics of the personal profile of users of social networks, act as indicators (predictors) of the results of such interaction. Therefore, the personal profile metrics with which the user works in social networks are a reflection of his intellectual-activity mechanism and act as cognitive (internal space-time) - behavioural (external activity) predictors - indicators that allow to predict the success of a person (in this study these are students) in real life within the various forms of its life activity.

One of the manifestations of a person's life activity is its educational activity, an indicator of which can be its academic success. Academic success is a variable of this study, which was chosen as an assessment of the predictive capabilities of social networks for predicting the characteristics of the life activity of its users.

At the second stage of the research, together with IT experts an information-analytical system was developed that allows monitoring the personal profiles of users of the "Vkontakte" social network (profiles that are open for access) and anonymizing data.

At the third stage of the research, statistically significant correlations of student's academic success with quantitative indicators of their personal profile metrics in the social network "Vkontakte" were obtained (The Pearson correlation coefficient and The Spearmen correlation coefficient). In the study, these metrics are designated as cognitive-behavioural predictors of person's life activity (in this work we consider an academic success as one of the forms of manifestation of life activity) and act as predictive characteristics of human behaviour. And because real life activity of the social network's user is the primary, the features of his virtual behaviour are a secondary indicator. Therefore, we can talk about the influence of features of real behaviour on the virtual. Positive correlations are shown in Figure 1.

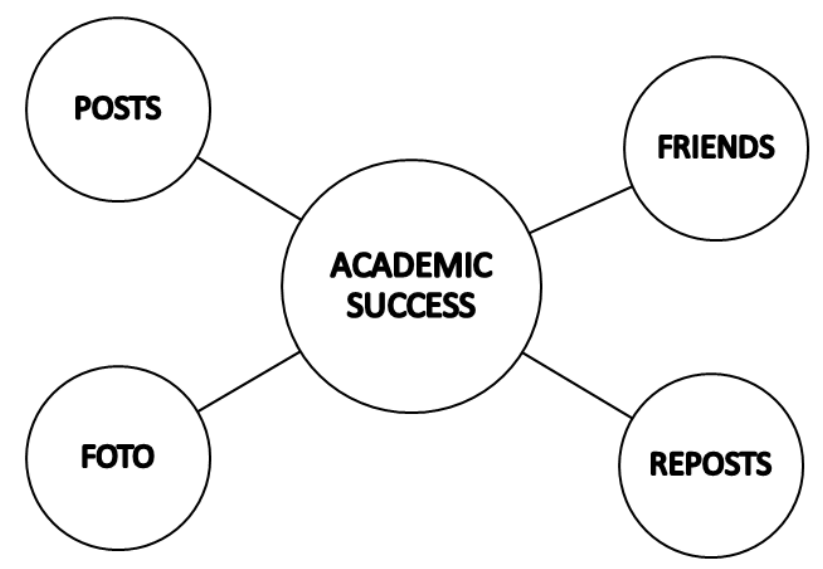

Figure 1. Positive correlations of academic success with the metrics of the personal profile of users of the "VKontakte" social network.

As seen in Figure 1., academic success has positive correlations with such metrics of the personal profile of a user of a social network as "Friends" ( $p \leq .01)$, "Photos" ( $p \leq .01)$, "Posts" ( $\leq \leq .01)$ and "Reposts" ( $\leq \leq$ $.01)$. 
Friends - this is an indicator of the number of friends which are shown in the user's personal profile in the social network "Vkontakte".

Photo - is an indicator of the number of photos displayed in the user's personal profile in the "Vkontakte" social network.

Posts - this is an indicator of the number of messages created by the user in his personal profile in the "Vkontakte" social network (productive activity).

Reposts - are an indicator of the number of copied posts created by other users of the "Vkontakte" social network (reproductive activity).

Thus, based on the results, the high academic success rate of students in their real life depends on their virtual activity in communications (number of friends), viewing photos, creating their own posts, and distributing other people's posts.

Next, in Figure 2 negative correlations are presented.

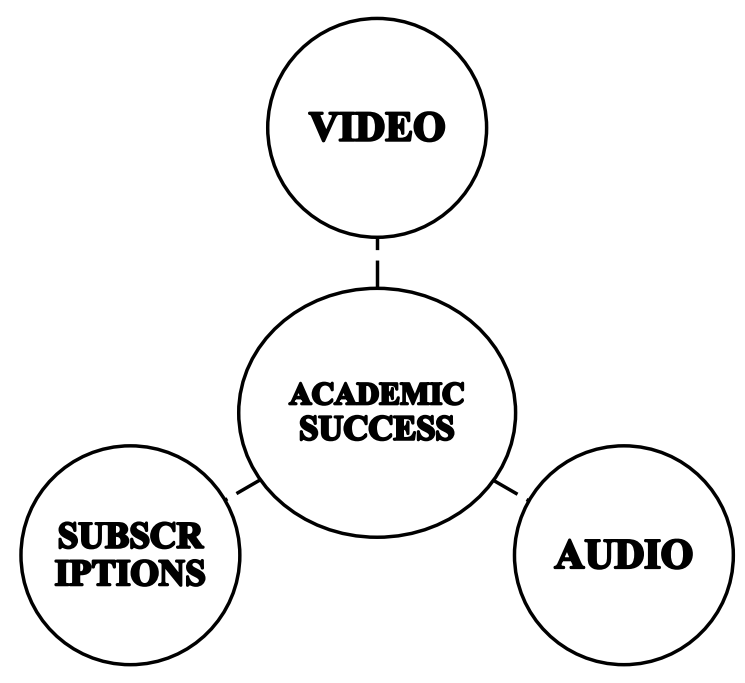

Figure 2. Negative correlations of academic success with the metrics of the personal profile of users of the "VKontakte" social network.

As seen in Figure 2, academic success has negative correlations with such metrics of the personal profile of a user of a social network as: "Video" ( $p \leq .01)$,"audio"( $p \leq .01)$,"Subscriptions" ( $p \leq .05)$.

Video - is an indicator of the number of videos displayed in the user's personal page in the "Vkontakte" social network.

Audio - is an indicator of the number of audio materials displayed in the user's personal profile in the "Vkontakte" social network.

Subscriptions - are an indicator of the number of interesting pages (forums, groups) that a user has subscribed to his personal profile in the "Vkontakte" social network. 
So, the low academic success rate of students in their real life depends on their virtual activity in viewing video and audio materials which are presented in their social network's personal page and on their subscribing to various interesting pages.

\section{DISCUSSIONS AND CONCLUSION}

According to the results of a study conducted by the Institute of psychology of the Russian Academy of Sciences among Russian experts in psychology, one of the priority directions of psychology development is the psychology of social networks and virtual reality. The study of the possibilities of assessing the characteristics of a person and predicting its behaviour using social networks is a subject area of psychology and related disciplines, which includes a wide range of issues. To solve these issues, significant efforts of scientific collaborations of researchers and a huge number of successful research projects are required. As an example, let us take the "MyPersonality project" - a collaboration of researchers that studies the psychological and demographic profiles of users of the social network Facebook.

The intensive virtualization of modern life both of an individual person and of society as a whole reflects the need to understand the laws of the relationship between cognitive and behavioural processes and their results in real and virtual life of the individual. In virtual reality, such processes and their results are presented as products of individual activity in social networks. The virtual behaviour of an individual (a user of social networks) in this study is understood as a multidimensional phenomenon, which includes various forms of its activity, in particular: the degree of openness (how much information is presented on a personal page); the degree of immersion (how long and often the personal page is visited by its owner); orientation of interests (reading, listening, watching); the degree of interest to other users ("likes"); focus on productive and reproductive styles of activity (user creates posts or distributes someone else's).

Among the various aspects of a person's real-life activity that can be studied from the perspective of their assessment and forecasting capabilities through psychometric indicators in social networks, the behaviour of academic success is selected. Academic success here refers to the educational achievements of an individual at the stage of his professional (social, life) self-realization.

The results of the study show the regularities of the ratio of academic success of students with the features of their virtual activity in social networks. These results require further understanding and additional research, followed by the creation of a theoretical and applied (structural and functional) model for predicting a person's life activity on the basis of intellectual and activity mechanisms of human interaction with the world and with oneself. The structural components of the model will be cognitive-behavioural predictors (prognostic parameters) that reflect the characteristics of a person's virtual activity in social networks.

The inclusion of this model in the subject area of future studies opens up new opportunities for psychology a significant expansion of its methodological apparatus. On the one hand, this inclusion will allow to take into account the changes that are taking place in the modern model of social reality. On the other hand, it will open up broad prospects for approaching the understanding of such a complex, multidimensional phenomenon as human behaviour in the real world and will provide opportunities for diagnosing and predicting behaviour through cyberspace.

A number of cognitive-behavioural predictors of the academic activity of the personality, which are presented in virtual reality as the results (products) of the processes of its activity in social networks through quantitative indicators of the metrics of its personal profile in social networks are highlighted. It is proved that the 
components of a personal profile (metrics) in social networks are the point of interaction between a real and a virtual personality. The category of "interaction", acting as a reflection of the life activity of a person, is the most adequate form of describing the mechanism that connects "I am real" with "I am virtual". This connection is manifested at three levels: cognition, adaptation, and transformation. One of the main manifestations of a person's virtual activity is social networks. Indicators (predictors) of the results of the interaction between a real and a virtual personality are cognitive-behavioural products, reflected in the metrics of the personal profile of users of social networks.

\section{ACKNOWLEDGEMENTS}

The study (all theoretical and empirical tasks of the research presented in this paper, except for the payment of publishing services) was supported by a grant from the Russian Science Foundation (Project No. 19-1800253, «Neural network psychometric model of cognitive-behavioural predictors of life activity of a person on the basis of social networks»).

\section{REFERENCES}

Baishya, D. \& Maheshwari, S. (2020). WhatsApp Groups in Academic Context: Exploring the Academic Uses of WhatsApp Groups among the Students. Contemporary Educational Technology, 11(1), 31 46. https://doi.org/10.30935/cet.641765

Blomfield Neira, C.J. \& Barber, B.L. (2014). Social networking site use: Linked to adolescents' social selfconcept, self-esteem, and depressed mood. Australian Journal of Psychology, 1(66), 56-64. https://doi.org/10.1111/ajpy.12034

Chen, L., Gong, T., Kosinski, M., Stillwell, D. \& Davidson, R.L. (2017). Building a profile of subjective well-being for social media users. PLoS One, 11(12), 1-15. https://doi.org/10.1371/journal.pone.0187278

Große, D.F., Mehl, M.R. \& Eid, M. (2014). Narcissistic power poster? On the relationship between narcissism and status updating activity on Facebook. Journal of Research in Personality, 53, 165 174. https://doi.org/10.1016/j.jp. 2014.10.004

Karakoyun, F. (2019). Preservice Teachers' Personality Traits and Social Network Use Purposes. Contemporary Educational Technology, 10(4), 399-415. https://doi.org/10.30935/cet.634190

Kosinski, M. (2017). Facial Width-to-Height Ratio Does Not Predict Self-Reported Behavioral Tendencies. Psychological Science, 11(28), 1675-1682. https://doi.org/10.1177/0956797617716929

Kosinski, M., Stillwell, D. \& Graepel, T. (2013). Private traits and attributes are predictable from digital records of human behavior. Proceedings of the National Academy of Sciences, 15(110), 5802 - 5805. https://doi.org/10.1073/pnas.1218772110

Lam, W.C.W. (2015). Exploring the Influence of Social Interaction, Pressure and Trust in a Social Media Environment on Political Participation: The Case of Occupy Central in 2014. Online Journal of Communication and Media Technologies, 5(4), 77-101. https://doi.org/10.29333/ojcmt/2527

Lau, W.W.F. (2018). Relationships between Pre-service Teachers' Social Media Usage in Informal Settings and Technological Pedagogical Content Knowledge. Eurasia Journal of Mathematics, Science and Technology Education, 14(12), em1611. https://doi.org/10.29333/eimste/94228

Manago, A.M., Taylor, T. \& Greenfield, P.M. (2012). Me and my 400 friends: The anatomy of college students' Facebook networks, their communication patterns, and well-being. Developmental Psychology, 2(48), 369 - 380. https://doi.org/10.1037/a0026338 
Hung, T. T. (2020). Preventing human trafficking in Vietnam through economic empowerment programmes. International journal of criminology and sociology, 9, 1-8. https://doi.org/10.6000/19294409.2020.09.01

Mulenga, E.M. \& Marbán, J.M. (2020). Is COVID-19 the Gateway for Digital Learning in Mathematics Education?. Contemporary Educational Technology, 12(2), ep269. https://doi.org/10.30935/cedtech/7949

Kislyakov, P. A., Shmeleva, E. A., Sergeev, S. E., \& Kulikov, S. B. (2020). Social Justice Based on Religious Forms of Prosociality in Russia. International Journal of Criminology and Sociology, 9, 6373.

Mwangi, E.W., Gachahi, M.W. \& Ndung'u, C.W. (2019). The Role of Mass Media as a Socialisation Agent in Shaping Behaviour of Primary School Pupils in Thika Sub-County, Kenya. Pedagogical Research, 4(4), em0048. https://doi.org/10.29333/pr/5950

Nave, G., Minxha, J. \& Greenberg, D.M. (2018). Musical Preferences Predict Personality: Evidence From Active Listening and Facebook Likes. Psychological Science, 7(29), 1145-1158. https://doi.org/10.1177/0956797618761659

Owan, V.J., Ekpe, M.B. \& Eneje, S. (2020). Undergraduates' Utilization of Social Networking Media and Sexual Behaviours in Higher Education: A Case Study. Pedagogical Research, 5(2), em0062. https://doi.org/10.29333/pr/7940

Radwan, E. \& Radwan, A. (2020). The Spread of the Pandemic of Social Media Panic during the COVID19 Outbreak. European Journal of Environment and Public Health, 4(2), em0044. https://doi.org/10.29333/ejeph/8277

Schwartz, H.A., Eichstaedt, J.C., Kern, M.L., Dziurzynski, L., Ramones, S.M. \& Agrawal, M. (2013). Personality, Gender, and Age in the Language of Social Media: The Open-Vocabulary Approach. Plos One, 8(9), 146-157. https://doi.org/10.1371/journal.pone.0073791

Seidman, G. (2013). Self-presentation and belonging on Facebook: How personality influences social media use and motivations. Personality and Individual Differences, 3(54), 402-407. https://doi.org/10.1016/j.paid.2012.10.009

Simsek, A., Elciyar, K. \& Kizilhan, T. (2019). A Comparative Study on Social Media Addiction of High School and University Students. Contemporary Educational Technology, 10(2), 106-119. https://doi.org/10.30935/cet.554452

Solmaz, O. (2018). A Critical Review of Research on Social Networking Sites in Language Teaching and $\begin{array}{llll}\text { Learning. } \quad \text { Contemporary } \quad \text { Educational } & \text { Technology, }\end{array}$ https://doi.org/10.30935/cet.444120

Sorokowski, P., Sorokowska, A., Oleszkiewicz, A., Frackowiak, T., Huk, A. \& Pisanski, K. (2015) Selfie posting behaviors are associated with narcissism among men. Personality and Individual Differences, 85, 123 - 127. https://doi.org/10.1016/j.paid.2015.05.004

Tazghini, S. \& Siedlecki, K.L. (2013). A mixed method approach to examining Facebook use and its relationship to self-esteem. Computers in Human Behavior, 3(29), 827 - 832. https://doi.org/10.1016/..chb.2012.11.010

Wang, Y. \& Kosinski, M. (2018). Deep neural networks are more accurate than humans at detecting sexual orientation from facial images. Journal of Personality and Social Psychology, 2(114), 246257. https://doi.org/10.31234/osf.io/hv28a

Zyoud S.H., Sweileh W.M., Awang R. \& Al-Jabi S.W. (2018). Global trends in research related to social media in psychology: Mapping and bibliometric analysis. International Journal of Mental Health Systems, 12, 1-8. https://doi.org/10.1186/s13033-018-0182-6 


\section{(c) $)(1) \Theta(9)$}

This work is licensed under a Attribution-NonCommercial-NoDerivatives 4.0 International (CC BY-NC-ND 4.0). 